\title{
S56. Suicide and aggression
}

PSYCHOLOGICAL SUPPORT OF STAFF AFTER AGGRESSIVE INCIDENCE ON PSYCHIATRIC WARDS.

Omerov M, Forsberg L, Bejhed L \& Wistedt B

Dept of Psychiatry, Karolinska Institute, Danderyds Hospital,

S-182 88 Danderyd, Sweden

Aggressive incidents of violence during psychiatric care results in a complex array of reactions by the staff and patients. This article describes the development and use of a programme intended to improve psychiatric skills to predict, and by different treatment strategies to diminish the incidence of violence. In case of violence the staff is given the opportunity to express and discuss their feeling with a special group of experts. The programme consist of an educational part focusing on prediction and "understanding" the aggressive behavior $i$ e provoking factors. If, in spite of all these precautions, an aggressive incidence occurs, staff meeting are held. As soon as possible after the event a group session using a form of debriefing technology on a cognitive basis is hold. In a later review conference "aggression autopsy" is performed.
AUTO-AGGRESSION AND SEROTONIN; A META ANALYSIS

S Tuinier, WMA Verhoeven

Vincent van Gogh Institute for Psychiatry, Dept. Biological Psychiatry, P.O. Box 5, 5800 AA Venray, The Netherlands

There is some evidence that abnormalities in the central serotonergic neurotransmission are involved in outward directed aggressive behavior or, more likely, in behavioral disinhibition in general. Autoaggression in the form of suicide or suicide attempts, self-mutilation and self-injurious behavior in mentally retarded patients seem also to be associated with disturbed central serotonergic neurotransmission, although the evidence in the case of non-suicidal self-destructive behavior is meager. Overviewing the data, the hypothesis can be formulated that diminished serotonin metabolism in the CNS might be related to dysregulated aggression, irrespective of the direction it takes and of the nosological context in which it occurs. The interpretation of the data about such biochemical disturbances in the CNS, as reflected by lower levels of CSF 5-HIAA, has to be done coutiously. Several confounding factors have to be accounted for of which the most important are: the influence on CSF 5-HIAA levels of coexisting factors like disturbed sleep pattern, circadian rhythm abnormalities or motor activity; the stability of CSF measurements over time in subjects with impulse regulation disturbances; the association of CSF 5-HIAA levels with different aspects of the aggressive behavioral spectrum.

It can be concluded that the serotonin hypothesis for (and) aggression is so far not well elucidated and that serotonin might be a non-specific modulator of behavior. Thus, a coherent and testable hypothesis has to be formulated how serotonin actually may regulate or modulate complex behavioral processes. 
CATECHOLAMINERGIC FUNCTION AND SUICIDAL BEHAVIOR W. Pitchot, M. Hansenne, A Gonzalez Moreno, J. Wauthy, M. Ansseau

Psychiatric Unit, C.H.U. du Sart Tilman, B-4000 Liège, Belgium

The current main neurochemical theories about the biological correlates of suicidal behavior principally involve the serotonergic system. Few data are available about the possible role of the catecholaminergic (noradrenergic and dopaminergic) neurotransmission. In the present study, we assessed the growth hormone (GH) response to clonidine $(0.15 \mathrm{mg}$ iv), a selective $\alpha 2$ adrenergic agonist, and apomorphine $(0.5 \mathrm{mg} \mathrm{sc})$, a dopaminergic agonist, in 30 DSM-III-R major depressive inpatients $(22 \mathrm{M}, 8 \mathrm{~F})$ with a history of suicide attempts, compared to 30 age- and gendermatched major depressive inpatients without history of suicidal behavior. The two groups differed significantly in the GH peak response to apomorphine : $6.7 \pm 3.5 \mathrm{ng} / \mathrm{ml}$ in suicide attempters vs $16.3 \pm 14.1 \mathrm{ng} / \mathrm{ml}$ in nonattempters $(F=13.2, p=0.0006)$. The suicide attempters tended to exhibit a lower GH peak response to clonidine than nonattempters, but the difference did not reach statistical significance : $3.56 \pm 4.0 \mathrm{ng} / \mathrm{ml}$ vs $5.6 \pm 4.8 \mathrm{ng} / \mathrm{ml}(F=3.21$, $p=0.07$ ). These results suggest that a dopaminergic deficit, as shown by a blunted GH response to apomorphine, could represent a biological correlate of suicidal behavior. In contrast, noradrenergic disturbances, particularly at the level of $\alpha 2$ adrenergic receptors, seem to play a more minor role.

SUICIDAL CAILERS IN THE TELEPHONE HELPLINE UNIT OF ATHENS

V P Kontaxakis, G N Christodoulou, M Stylianou, K Polychronopoulou

Center for Mental Health, 58 Notara str, 10683 Athens, Greece

The Telephone Helpline Unit (THU) of Athens, covers the entire spectrum of psychological problems that can lead a person to a situation of crisis. The THU is staffed by psychologists, psychiatric residents and social workers. The staff members of the THU are specially trained for crisis intervention. The main scope of the THU is psychological (emotional) support, counselling and referral for people under psychological crisis. From a random sample of 4586 callers seeking help by phone during a two-year period (1987-1989), 473 (10.3\%) stated their suicidal ideation as primary reason for calling (Group A). Suicidal callers ( $N=473$, Group $A$ ) were compared in many parameters (age, sex, marital status, education, employment status, time of calling, call duration, use of psychotropic drugs, family, marital or financial problems etc) to non-suicidal callers ( $\mathrm{N}=4113$, Group $\mathrm{B})$. For the statistical evaluation the SPSS package was used (statistical criterion $\mathrm{x}^{2}$, correlation coefficient PRi- $\phi^{2}$ or Cramer's V). The differential characteristics of the suicidal callers are the following: older in age $(p<0.05)$, more of ten widower or separated ( $p<0.001)$, unemployed or - pensioner ( $p<0.001)$, with family, marital or vocational problems or problems related to alcohol abuse $(p<0.001)$. They more of ten were depressive and anxious ( $<<0.001)$, used psychotropic drugs ( $p<0.001)$ and were calling in the night time $(p<0.003$ ) with calls of longer duration $(p<0.001)$.

\section{SUICIDE AND GENDER}

M Sarchiapone, P Bria, A Ciocca and S De Risio

Institute of Psychiatry and Psychology, Catholic University of S.H. of Rome, L.go A. Gemelli, 1. 1-00168, Rome, Italy.

In the suicide the relationship between male and female show usually the prevalence of male. In this work we have studied the distribution of male and female among 67 suicides in a little mountain country of the center of Italy from 1946 to 1993.36 of 67 suicides were female and 31 were male. Because the almost part of the suicides have born and lived in the suburbs around the town, we have evaluated the quality life, by a psychosocial interview in a random champion of population, and the hostility, by the Buss - Durkee Hostility Inventory among 121 relatives of 19 suicides. The data obtained by the psychosocial interview show a probable influence, above all in the past, of the social carachteristics on the urban distribution of suicide and a major tolerance by women at these. The data obtained by the Buss - Durkee Hostility Inventory show a high T score of female $(57,41$ Tp) vs male $(53,16 \mathrm{Tp})$.
PREVALENCE OF SOCIAL PHOBIA AMONG SERIOUS SUICIDE ATTEMPTERS

M ABBAR, MD 1 , JM CHIGNON, MD² Y CAER, MD 3 MC PICOT, MD 4 PCOURTET, MD1 D DASTENAU, MO 3

${ }^{1}$ Service de psychiatrie et de psychologie médicale, Hopital Carémeau, 30000 Nímes France

2 Anxiety clinic, Psychiatry departement, Hopital Bichat-Claude

Bernard 75018 Paris France

${ }^{3}$ Service de psychiatrie et de psychologie médicale, Hopital Lapeyronie 34000 Montpeilier France

4 Departement d'information médicale. Hopital Lapeyronie 34000 Montpellier France

Recently, some authors have reported that social phobia in the community could be associated with significant morbidity. Particularly, comorbid social phobia was found associated with an increased rate of suicide attempts.

We assessed 150 serious suicide attempters, 52 males and 98 females, who were hospitalized immediately after their suicidal gesture. All patients were evaluated with a modified version of the SADS-LA which authorize the use of DSM-III-R criteria for axis I psychiatric diagnoses and comorbidity. Mean age of the population was 35.5 (SD:13.7) years.

Twenty-three patients $(15.3 \%$ ) (6 men and 17 women) suffered from social phobia. Ninety-three patients $(62.0 \%)$ suffered from current Major Depressive Episode, 29.3\% from Panic Disorder, 26.7\% from addictive disorders. Women were more likely to have an history of depressive disorders $(60.2 \%$ vs $48.1 \%$ : $p<.05)$ but, addictive behaviours were more prevalent in males $(57.7 \%$ vs 12.2 : $p<10-3)$. The number of lifetime comorbid diagnoses was similar in males and in females $(2.0 \pm 1.3$ vs $1.7 \pm 1.3 ;$ NS $)$. At the time of the index episode, 23 patients (15.3\%), 5 males and 18 females, did not suffered from any Axis I diagnose.

Among patients with social phobia, we found a high rate of comorbidity. In fact, $78.3 \%$ of them reported having suffered from major depressive episode in their life, $43.5 \%$ from panic disorder and $10.8 \%$ from alcohol abuse and or dependance.

So, it appear that the rate of social phobia is high in suicide attempters and that social phobia may interact with some comorbid disorders in regard to increased risk of suicide attempt. 


\section{YOUNG SUICIDE ATTEMPTERS : DIFFERENT TYPES OF} PSYCHIATRIC CARE (A LITERATURE REVIEW)

\section{WALTER, A. LAZARTIGUES,J.J, KRESS}

Services Hospitalo-Universitaires de Psychiatrie, CHU MORVAN - 29609 BREST Cedex - FRANCE

Based on a literature review about precoce care to young suicide attempers, this paper presents two important patterns of care : the institutional and the ambulatory type.

The institutional type offers several places of hospitalization, either in a specific psychiatric environment (crisis center, specialized unit for adolescents and young adults), or in paediatrics or in medicine, or in a classical psychiatric environment.

The ambulatory type is based on the setting up, following different modes here again, of specialized consultations (individual and familial interviews, brief psychotherapies, crisis interaction and intervention) followed or not by a secondary intervention.

Psychopharmacological treatment and a social care linked to it are also considered as important.

The impact of these various approaches is usually valued by the repeated attempt rate and the suicide rate, the therapeutic attendance, the symptomatic (SCIDI, BPRS, SCAN), social (GAF, SAS) and familial outcome in the short, middle and long term.

However, the heterogeneousness of the proposed cares and assessments would require the elaboration of more rigourous protocols. 